\title{
New Exploration of CFRP prestressed equipment
}

\author{
L. XU \& C. ZHAO \\ University of Science and Technology Liaoning \\ SCHOOL OF CIVIL ENGINEERING
}

KEYWORDS: Carbon Fiber Reinforced Polymer; Prestressed equipment;Reinforcement

ABSTRACT: CFRP is widely used in the area of reinforcement because of its many advantages, but ordinary methods of past can not give full play to high-strength properties of CFRP.Therefore, new technology of concrete structures strengthened with prestressed CFRP emerges as the times require. At the same time,the prestressed tensioning equipment as the main construction tools has become a top priority. In this paper, we explored a new set of CFRP prestressed equipment, which is suitable for laboratory use through a comparative study of the existing applying ways and tensioning equipment of prestressed CFRP, and made use of the equipment to conduct the experimental research on strengthening concrete beams with prestressed CFRP.Experiment shows that the concrete beams strengthened with prestressed CFRP improved more significantly than the ones strengthened with ordinary CFRP in the aspects such as the bearing capacity. Thus it can be seen that the reinforcement effect is good, and the equipment can be further studied and applied to practical engineering.

\section{The research background and significance}

People to the requirement of security, applicability and durability of the building is increasing along with the rapid development of the whole society ${ }^{1]}$, at the same time, the buildings need reinforcement treatment because of fire, earthquake and other force majeure caused damage to building structure part or quality problems caused by design and construction defects ${ }^{[2]}$, make the structure protected in various aspects and continue to play its original role.

In recent years, the trend in the research of fiber materials is set off at home and abroad ${ }^{[3-5]}$, a variety of fiber materials emerge as the times require with the development of the material technology. In the existing research results, carbon fiber material is a kind of high-tech materials which is currently applied in the field of civil engineering as its features of the longest time, the largest amount and the most widely used. Compared with the original strengthening methods, carbon fiber reinforcement technology has its obvious technical advantage, it has many advantages like high strength and efficient, good corrosion resistance and durability, it does not increases the weight and volume of the artifacts, widely applicable, convenient for construction etc, therefore, the study of carbon fiber reinforcement technology has important practical significance and application value. But with the deepening of the theoretical research and practical application of the project, the problems existing in the carbon fiber have gradually emerged:

(1) High strength performance of CFRP can not fully play ${ }^{[6]}$, the structure of the deformation and development of fracture are difficult to be effectively suppressed, and the strengthening efficiency is not high.

(2) The degree of improvement on the cracking load of the component in the normal phase and the maximum crack width is not obvious.

These problems limit the progress of CFRP on its reinforcement in the construction, a lot of research showed that if add the prestress to the CFRP at first, and then reinforce the structure ${ }^{[7]}$, it can greatly improve the reinforcement effect. Application of prestressed CFRP can both restrain the early appearance of concrete cracks and avoid the peeling phenomenon of CFRP and concrete which is caused by the stress concentration.

\section{The current research status of related fields at home and abroad}

\section{The current research status of related fields at home}

(1) Anti arch technology First of all, paste the CFRP firmly at the bottom of the beam, and then make the jack play a role at the mid-span position of the bottom of the beam, so there will be an anti 
arch in the mid-span position, wait until the civil adhesive which is used to paste the CFRP reaches a certain intensity, the jack will be removed, so the CFRP can be stretched during the process of beam to restore its weight and elasticity, therefore the whole structure is in the state of prestress, the construction process is shown in Figure 1.

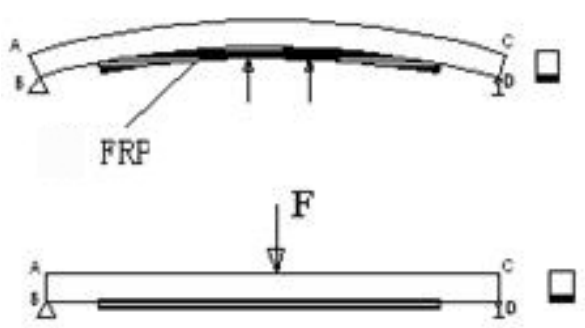

Figure 1 The anti arch construction technology diagram

(2) Using the tensioning equipment to tense directly Make use of the tensioning equipment to tension the CFRP, paste the CFRP which is under the load condition to the bottom of beam, stay after the epoxy resin reaches a certain intensity, then release the prestress, at the same time do well in the aspect of end anchorage, the prestressed construction process is shown in Figure 2.

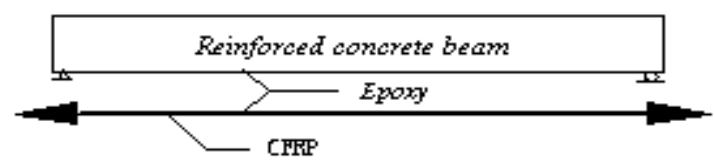

(a) Pre tensioning on CFRP

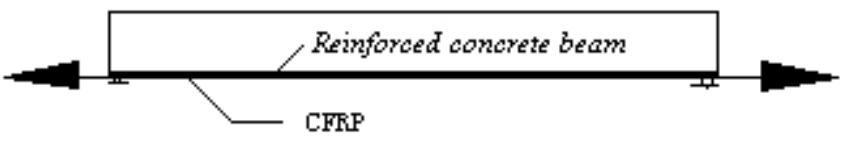

(b) Paste and maintenance

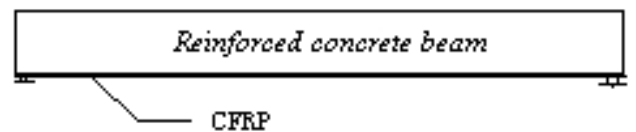

(c) Release the tension side

Figure 2 Prestressed construction tensioning equipment diagrams

(3) Add prestress on CFRP through the interaction between CFRP and concrete beam, as shown in Figure 3. The working principle of the device is: form a loop in the process of prestressing on CFRP through rollers, make the lever hoist and force sensor are respectively connected with the two free ends of the CFRP, and then use the lever hoist to tighten the CFRP and prestress on it.

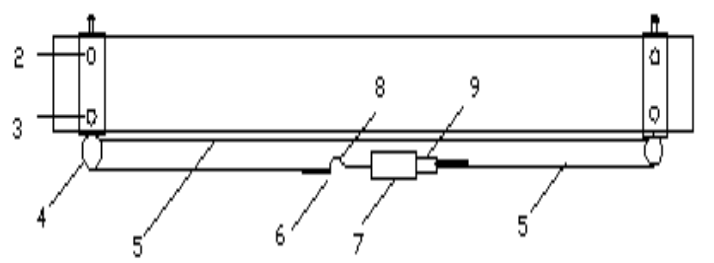

(1) Lifting device ;(2) Steel plate;(3) Bolt;(4) Roller;(5)CFRP;(6) Fixture;(7) Lever hoist; (8)Hook;(9) Force sensor Figure 3 Lever hoist construction process diagram 


\section{The current research status of related fields at abroad}

(1)G.Sakar ${ }^{[8]}$ and others made a simple test equipment used to prestress on CFRP, and use the prestressed CFRP to reinforce the concrete beams, the bending destructive test found that the ultimate strength of the specimens and bending performance have improved significantly, it shows that the prestressed CFRP can give full play to its high performance.

(2) P. Neto ${ }^{[9]}$ and others analyzed and compared the test results of prestressed CFRP reinforced concrete beams by using the numerical simulation, the simulation was conducted with the method of discrete fracture modeling, at the same time, using the method of non linear iterative sequence in order to avoid causing problems such as convergence, finally the results of numerical simulation tally well with the test results.

\section{The prestressed equipment in this paper}

Aiming at the shortage of the existing method of prestressing, the author explored a prestressed equipment which is suitable for laboratory and to solve the problem of medium and small span beam and plate reinforcement through repeated practice and research. Because of the way of prestressing on the CFRP is particular, so the construction equipment should have the following properties:(1) it can effectively tension the CFRP;(2) in order to ensure that the CFRP under the larger force will not be pulled by uneven stress soon, anchor device and the device itself should have larger stiffness;(3) it should be light enough for transportation and installation.

After repeated studies and experiments, this article proposed test unit with all the above properties, it is composed of two pieces of steel plates with the sectional dimension of $600 \times 200 \mathrm{~mm}$ and the thickness of $10 \mathrm{~mm}$, four screw rods of A14mm,eight nuts with diameter of $14 \mathrm{~mm}$ and eight gaskets with diameter of $15 \mathrm{~mm}$, a inserted plate with the sectional dimension of $120 \times 80 \mathrm{~mm}$ and the thickness of $10 \mathrm{~mm}$,a iron hoop with diameter of $10 \mathrm{~mm}$ and the sectional dimension of $280 \times 240 \mathrm{~mm}$,a tension meter, a turn-buckle of A20mm, two round tubes with the length of $110 \mathrm{~mm}$ and the diameter of A15 mm and two reinforcement plates with sectional dimension of $180 \times 120 \mathrm{~mm}$ and the thickness of $5 \mathrm{~mm}$. One of the reinforcement plates is welded to one end of the turn-buckle, the other end of the turn-buckle and the tension meter is connected together to show the size of the prestress directly, each part of the device name and connection mode as shown in Figure 4.

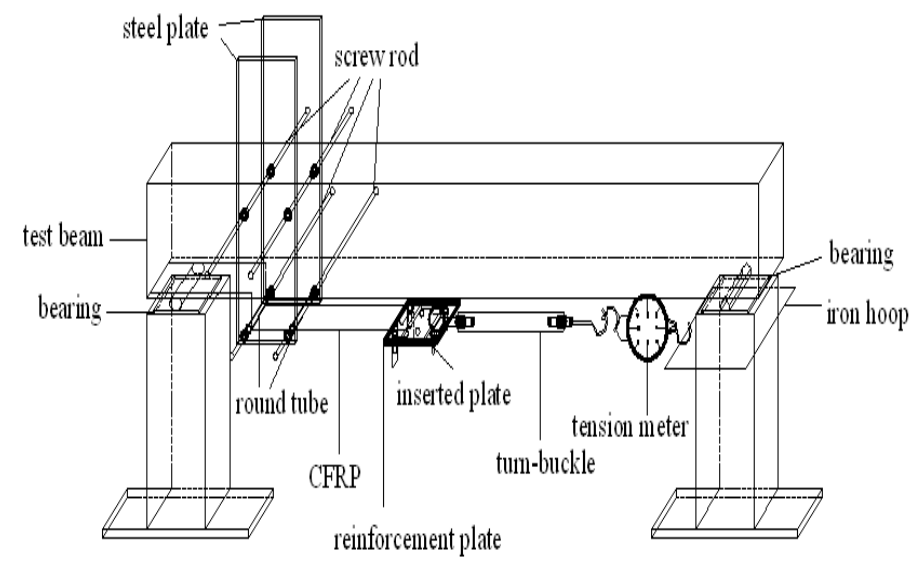

Figure 4 Prestressed equipment connection diagram of each part

\section{The application of CFRP prestressed equipment}

(1) Surface treatment ${ }^{[10]}$ Grind the surface of the concrete which is pasted with the angle grinder, remove surface impurities until new concrete interface appears completely.

(2) Clean the surface Before pasting the CFRP, the bottom of the beam v the surface location of the beam which needs to be pasted the shear u-shaped hoop and the CFRP should be cleaned with acetone, in order to prevent the contamination and affect the quality of pasting.

(3)Paste the CFRP Measure the two kinds of civil adhesives with measuring cylinder according to certain proportion, daub it evenly on the beam surface which need to be pasted, and paste one end 
of the CFRP on one end of the beam quickly within the stipulated time, make the roller go along the stress direction of the CFRP repeatedly to roll out of the bubbles, so that the CFRP is closely pasted with component surface.

(4)Connect the device The four A14 screw rods are respectively penetrated into the corresponding bolt hole, connect two pieces of steel plate and fixed at one end of the component, forming a fixed pulley system to make the CFRP closely pasted with component surface, pass the other end of the CFRP over the elliptical hole on the reinforcement plate which is not welded with the turnbuckle, and make the inserted plate and the other reinforcement plate that welded with the turnbuckle tightly compacted on it, finally bolted. The other end of the turn-buckle is connected with the tension meter; the other end of the tension meter is fixed on the iron hoop that set on the bearing in advance, uses the ripper to exert force and reads the size of the prestress by the tension meter directly.

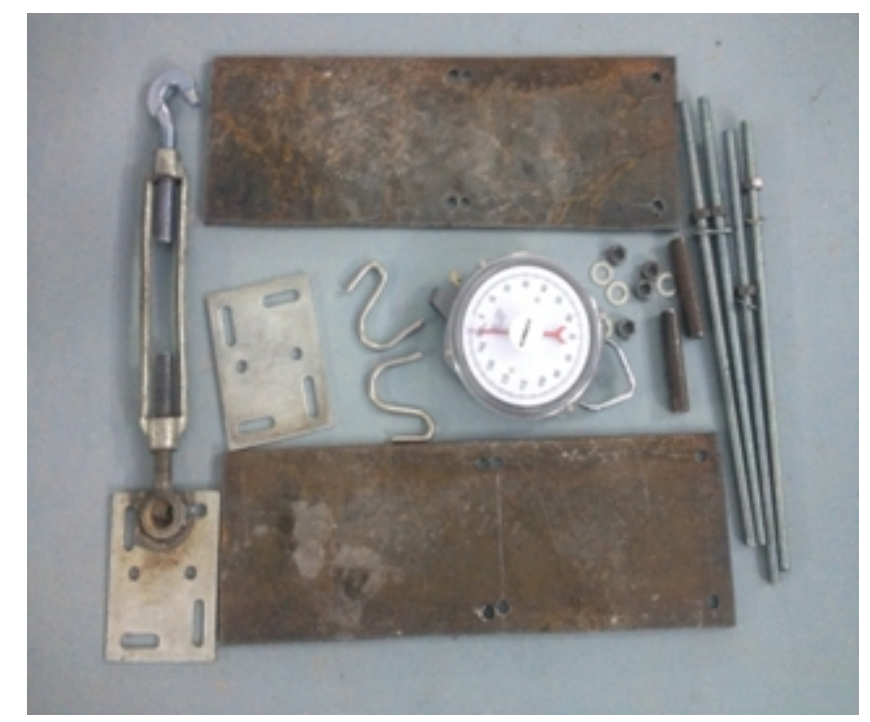

Figure 5 The equipment diagram of each component

\section{Conclusion}

Compared with the existing tensioning device of prestressed CFRP, the significant beneficial effects of the invention are as follows:

(1) The fixed pulley system and fixture are unique, the two can coordinate with each other to complete the prestress applied on the CFRP without anchorage, simple and easy, and to ensure the CFRP is closely pasted on the surface of the component.

(2)The turn-buckle is a smart application, one end is welded together with the reinforcement plate as fixture, and the other end is connected with the tension meter directly, during the process of prestressing, the size of the prestress is clear at a glance.

(3)The use of iron hoop is just perfect, it greatly reduces the complexity of construction, and makes a good effect on fixing, at the same time it avoids the problem of the large-scale dedicated tensioning machine because of its heavy, the equipment has the advantage of simple structure, it is easy to produce and it is light and practical.

(4)The way of prestressing is easy and convenient, it eliminates the complexity of the mechanical facilities in the process of prestressing, therefore it reduces the cost of reinforcement engineering; the reinforcement effect is good, it can give full play to the performance of carbon fiber materials, reduce the loss of prestressed CFRP and the amount of CFRP.

In summary, the device has so many advantages that can be further studied and applied in practical engineering. 


\section{References}

[1].T Zhao, J Xie. The carbon fiber cloth reinforcement technology of concrete structures [M]. Tianjin: Tianjin University press, 2001. (in Chinese)

[2].H.Q. Wei, Y Zhang, X.X.Huang. Study construction technology of concrete beams strengthened with prestressed CFRP [J]. Industrial construction, 2005, 35 (11): 90-93. (in Chinese)

[3]. Imran A. Bukhari ,Robert Vollum ,Saeed Ahmad,etc. ,Shear Strengthening of short span Reinforced Concrete Beams with CFRP Sheets[J].Arabian Journal for Science and Engineering ,2013, $38(3)$, pp523-536.

[4]. Mohammad Z. Kabir,M. Eshaghian. Flexural Upgrading of Steel-Concrete Composite Girders Using Externally Bonded CFRP Reinforcement[J].Applied Composite Materials, 2010, 17(2), pp209-224.

[5]. M.Tigeli ,P.Moyo ,H. Beushausen. Behaviour of Corrosion Damaged Reinforced Concrete Beams Strengthened Using CFRP Laminates [J]. Nondestructive Testing of Materials and Structures, 2013,6,pp1079-1085.

[6]: R. Q. Ou. Study of prestressed CFRP reinforced concrete beam bending performance [D]. Nanjing: Nanjing University of Aeronautics \& Astronautics, 2006. (in Chinese)

[7]. Q. Lei, G.F.Wei. Study on CFRP prestressing method [J]. The western exploration engineering, 2007, 10:184-185. (in Chinese)

[8]. G. Sakar, H. M. Tanarslan. Prestressed CFRP Fabrics for Flexural Strengthening of Concrete Beams with an Easy Prestressing Technique[J].Mechanics of Composite Materials , 2014,50(4),pp537-542.

[9]. P. Neto, J. Alfaiate, J. Vinagre. Numerical modeling of concrete beams reinforced with prestressed CFRP [J]. International Journal of Fracture, 2009, 157(1-2), pp159-173.

[10].X.L.Huang ect. The identification, reinforcement and increasing storey of buildings[M]. Beijing: Chinese Building Industry Press, 2008. (in Chinese) 